\title{
Mercury in ash materials and fluvial transport of mercury in watersheds following wildfire
}

\author{
$\underline{\text { PEIJIA KU }}^{1}$, MARTIN TSUI $^{1 *}$, RANDY DAHLGREN ${ }^{2}$, \\ ALEX T. $\mathrm{CHOW}^{3}$ \\ ${ }^{1}$ University of North Carolina at Greensboro, Greensboro, \\ North Carolina 27402, United States (p_ku@uncg.edu), \\ (*correspondance: tmtsui@uncg.edu) \\ ${ }^{2}$ University of California Davis, Davis, California 95616, \\ United States (radahlgren@,ucdavis.edu) \\ ${ }^{3}$ Clemson University, Clemson, South Carolina 29634, \\ United States (achow@.clemson.edu)
}

Wildfires are expected to become more frequent and intense at the global scale due to climate change. However, little is known about alterations in the biogeochemical pool of mercury $(\mathrm{Hg})$ in wildfire ash materials in post-burn landscapes, as well as the post-burn hydrological response of $\mathrm{Hg}$ transport. In our study, we examined $\mathrm{Hg}$ levels and reactivity in wildfire ash generated from two northern California wildfires, and found that all ash samples contained measurable but highly variable $\mathrm{Hg}$ levels (up to $125 \mu \mathrm{g} / \mathrm{kg}$ ). $\mathrm{Hg}$ isotopic analysis suggested that the $\mathrm{Hg}$ in the ash was derived from the vegetation, not from atmospheric $\mathrm{Hg}$ deposition. Interestingly, ash samples had a highly variable fraction of $\mathrm{Hg}$ in recalcitrant forms $(0-75 \%)$, and this recalcitrant pool of $\mathrm{Hg}$ appears to be associated with the aromatic carbon fraction in ash. Ash samples were found to strongly sequester aqueous inorganic $\mathrm{Hg}$ and more importantly inhibit methylmercury ( $\mathrm{MeHg}$ ) production under anoxic conditions. Notably, the post-burn fluvial transport of $\mathrm{Hg}$ is mainly mediated by suspended solids, including ash and fine soil particles in the burned watersheds. The "first flush" in the winter after the previous summer wildfire is particularly important in transporting large quantities of total $\mathrm{Hg}$ and $\mathrm{MeHg}$. In contrast, $\mathrm{Hg}$ export significantly declined in the second winter following the summer wildfire. This study demonstrates the impact of wildfires on $\mathrm{Hg}$ biogeochemical cycling in both terrestrial and aquatic environments as well as their rapid recovery one year after the wildfire. 